\title{
Effects of poly(ethylene oxide) and ZnO nanoparticles on the morphology, tensile and thermal properties of cellulose acetate nanocomposite fibrous film
}

\author{
Chonticha Pittarate ${ }^{1}$, Tipaporn Yoovidhya ${ }^{1}$, Walaiporn Srichumpuang ${ }^{1}$, Narupol Intasanta ${ }^{2}$ and \\ Saowakon Wongsasulak ${ }^{1}$
}

A bio-based fibrous film intended to be used as a food-packaging component was electrospun from blend solutions of cellulose acetate (CA) in neat acetic acid and poly(ethylene oxide) (PEO) in $90 \%$ ethanol. The CA/PEO blend ratios were varied to determine the effects of PEO on the morphology, moisture-adsorption and tensile properties of the blended fibrous films. Zinc oxide nanoparticles ( $\mathrm{ZnO} N \mathrm{NP}$ ) incorporated $(2-20 \mathrm{wt} \%$ of PEO) into the blended fibers were tested for their effect on tensile and thermal properties of the nanocomposite films. The results indicated that the addition of PEO at $9 \mathrm{wt} \%$ improved tensile strength, elongation and elasticity $(P<0.05)$ of the $\mathrm{CA}$-based fibrous films. The energy-dispersive spectrometer-scanning electron microscopy results suggested that zinc elements were well dispersed in the CA-PEO-blend fiber matrix. The addition of $\mathrm{ZnO}$ NPs at $\mathbf{2 0}$ wt\% of PEO led to a significant improvement in the elongation and tensile strength of the CA-PEO-blend fibrous film $(P<0.05)$. This improvement was attributed to the association between ZnO NPs and the semi-crystalline structures of the PEO, as evidenced by differential scanning calorimetry thermograms and X-ray diffraction spectra.

Polymer Journal (2011) 43, 978-986; doi:10.1038/pj.2011.97; published online 28 September 2011

Keywords: bio-based nanocomposite; cellulose acetate; electrospinning; mechanical property; ultrafine fibers

\section{INTRODUCTION}

Food-packaging and food contact surfaces (inner layer of the packaging) have become a source of concern in the food sector, because they do not provide basic protection or keep foods fresh. However, the potential for extending the shelf life of foods through microbial resistibility as well as prolonging the lag phase and reducing the growth rate of bacteria have been topics of academic and industrial interest. The incorporation of metal nanoparticles (NPs) into polymer film matrices has been noted as the most promising method of achieving the latter goal. ${ }^{1-6}$ The NPs offer an antimicrobial ability because of their extremely small particle sizes, which provide an extraordinarily high ratio of surface area to volume or surface area to weight as well as an innumerable number of active surfaces. Zinc oxide $(\mathrm{ZnO})$ has been reported as an interesting potential substance for use in foods in antimicrobial applications. It is stable under harsh processing conditions and is currently considered by the Food and Drug Administration as a generally recognized as safe material. ${ }^{2,7} \mathrm{ZnO}$ NPs have recently been reported as being an effective antibacterial agent for agricultural products and food protection with a minimal effect on human cells. ${ }^{2}$ The most relevant form of $\mathrm{ZnO}$ NPs for such applications is referred to as a 'nanocomposite.'1,4,6,7
Natural or bio-based materials have been developed to replace non-biodegradable polymeric packaging to address the serious problem of global warming. Cellulose acetate (CA) has attracted considerable attention as an environmentally friendly polymer for natural/bio-based packaging. The suitability of CA for this application is attributable to its desirable and unique properties, such as water insolubility, good thermal and chemical resistances and high transparency. CA and its derivatives, which are available for common use and are also recognized as non-toxic polymers, are prepared from renewable natural resources. However, CA films are rigid and brittle. The inclusion of organic and inorganic additives represents an effective route to the physical and mechanical modification of CA-based materials. ${ }^{8-13}$ Long linear chain molecular polymers, such as poly (ethylene oxide) (PEO), are expected to impart high flexibility to the CA matrix. PEO is one of the most biocompatible synthetic polymers; it is approved by the Food and Drug Administration for safe use in foods and pharmaceuticals. ${ }^{14}$ In particular, $\mathrm{ZnO}$ NPs have also been exploited as a functional nanofiller to improve the mechanical properties of CA films. ${ }^{6,15}$

As previously discussed, nanotechnology is now used to produce materials with extremely high surface-to-mass and surface-to-volume

${ }^{1}$ Department of Food Engineering, Faculty of Engineering, King Mongkut's University of Technology Thonburi, Bangkok, Thailand and ${ }^{2}$ National Nanotechnology Center (NANOTEC), National Science and Technology Development Agency, Phathumthani, Thailand

Correspondence: Dr S Wongsasulak, Department of Food Engineering, Faculty of Engineering, King Mongkut's University of Technology Thonburi, CB5-Floor 3rd, 126 Pracha u-tid Road, Bangkok 10140, Thailand.

E-mail: saowakon.won@kmutt.ac.th

Received 24 April 2011; revised 19 July 2011; accepted 4 August 2011; published online 28 September 2011 
ratios. Electrospinning is a well-known technique for the preparation of organic-inorganic hybrid fibers with diameters that range from the micrometer to the nanometer scale. The electrospun fibers are formed with exceedingly high surface-to-mass and surface-to-volume ratios, which generally exceed $1000 \mathrm{~m}^{2} \mathrm{~g}^{-1} \cdot{ }^{16}$ The fiber morphologies can be modulated by altering the solution properties of the precursor solutions as well as by modifying the electrospinning process parameters. Electrospun fibrous films have been extensively applied in biological, material and energy applications. However, fibers electrospun from biopolymers such as CA are very fragile. With the addition of NP and/or PEO, a long linear chain polymer with good electrospinnability might improve the tensile properties of the electrospun CA film. Nonetheless, the effect of NPs on an electrospun fiber's morphology and the tensile properties of the CA fibrous films have rarely been reported.

In this work, natural nanocomposite fibers were electrospun from a blended solution that contained CA, PEO and ZnO NPs. The effects of $\mathrm{PEO}$ and $\mathrm{ZnO} \mathrm{NPs}$ on solution properties (that is, viscosity, electrical conductivity and surface tension), which influence the morphology and tensile properties of the electrospun fibrous films, were investigated along with the thermal properties of the nanocomposite electrospun films.

\section{MATERIALS AND METHODS}

\section{Materials}

CA $\left(\mathrm{Mn}=30000 \mathrm{~g} \mathrm{~mol}^{-1}\right.$, acetyl content $=39.8 \%$; degree of acetyl substitution $\approx 2.4)$ and PEO $\left(\mathrm{Mn}=300000 \mathrm{~g} \mathrm{~mol}^{-1}\right)$ were purchased from Sigma-Aldrich, Buchs, Switzerland. ZnO NPs with an average particle size of $50-70 \mathrm{~nm}$ were purchased from Aldrich Chemicals (St Louis, MO, USA). Glacial acetic acid (AR grade, Carlo Erba, Milan, Italy), ethanol (commercial grade, Samsung Fine Chemicals, Seoul, Korea) and saturated salt solution of magnesium nitrate (Fisher Scientific, Fair Lawn, NJ, USA) were used as received.

\section{Methodology}

Preparation of primary polymer solutions. A CA primary stock solution $(20 \% \mathrm{w} / \mathrm{v})$ was prepared by the dissolution of $2 \mathrm{~g}$ of CA in $10 \mathrm{ml}$ of $99.9 \%$ acetic acid. The solution was then stirred for $2 \mathrm{~h}$ using a magnetic stirrer (Model C-MAG HS7, IKA, Guangzhou, China). A PEO primary stock solution $(3 \% \mathrm{w} / \mathrm{v})$ was prepared by the dissolution of $3 \mathrm{~g}$ of PEO in $10 \mathrm{ml}$ of $90 \%$ ethanol, and the solution was stirred for $2 \mathrm{~h}$ using a magnetic stirrer. These two conditions were selected from an optimized preliminary study, as reported in the section Preliminary study of polymer solution concentrations of CA and PEO.

Preparation of blended polymer solution. Mixed solutions with varying mass fractions of CA to PEO (100/0, 99.6/0.4, 98/2, 91/9 and $0 / 100)$ were prepared from the two primary stock solutions. The mixtures were stirred for $1 \mathrm{~h}$ before the solution properties were measured and before the fibers were electrospun. For $\mathrm{ZnO} \mathrm{NP}$ inclusion, $\mathrm{ZnO}$ NPs were first added to the primary PEO solution at 2, 10 and $20 \mathrm{wt} \%$ of PEO. The solution was then mixed with the primary stock solution of CA. As a result, the CA/PEO/ZnO weight ratios were 90.7/9.1/0.2, 90.1/9.0/0.9 and 89.3/8.9/1.8.

Viscosity measurements. The apparent viscosities of the mixed solutions were investigated using a modular compact rheometer (MCR 150, Physica, Österreich, Germany) with a CC17 probe. For measurement, a 5 -ml aliquot was added to a cup holder. The shear rate was set in the range of $0.01-400 \mathrm{~s}^{-1}$. The temperature of the sample was equilibrated to $25^{\circ} \mathrm{C}$ using a Peltier system (Physica) before the measurements. The reported data are the averages from triplicate measurements.
Surface tension measurements. The surface tension of a sample solution was measured using a digital tensiometer (Model DCT11, Dataphysics, Filderstadt, Germany) at $25^{\circ} \mathrm{C}$ by the ring method. A total of $20 \mathrm{ml}$ of sample solution was transferred to a $50-\mathrm{ml}$ glass beaker that was rinsed with double-deionized water. The surface tension at the maximum pulling force was recorded.

Electrical conductivity measurements. The electrical conductivity of the sample solutions was measured using a digital conductivity meter (CG855, Schott, Mainz, Germany). A 2-ml sample of the testing solution was transferred to the equipped glass tube. The measurements were conducted at $25^{\circ} \mathrm{C}$.

Electrospinning. Electrospinning solution of $10 \mathrm{ml}$ was transferred to a glass syringe equipped with a stainless steel needle (inner diameter of $0.69 \mathrm{~mm}$ ). The syringe was mounted on a syringe pump (NE 1000, New Era Pump Systems, Farmingdale, NY, USA) to control the feed rate in the range of $0.5-100 \mu \mathrm{min}^{-1}$. The stainless steel needle was connected to the high-voltage generator (ES30P-5W, Gamma High Voltage, Ormond Beach, FL, USA) in positive DC mode. A grounded copper plate was used to collect the electrospun particles (beads/fibers/ beaded fibers). The distance between the needle tip and the receiving copper plate was fixed at $20 \mathrm{~cm}$. All experiments were performed at $25 \pm 1{ }^{\circ} \mathrm{C}$ and with a relative humidity of $50 \pm 5 \%$.

Preconditioning of film samples. According to the preconditioning method described by Wongsasulak et al. ${ }^{17}$ for the testing of the mechanical properties of electrospun films, the resulting electrospun films were first dried in a vacuum oven at $40{ }^{\circ} \mathrm{C}$ for $24 \mathrm{~h}$ to remove any remaining solvent. The thicknesses of the solvent-free films were then measured using micrometer calipers (Model 102-309, Mitutoyo, Kanagawa, Japan) with a precision of $\pm 1 \mu \mathrm{m}$. For each film sample, the measurements were performed on 10 random positions close to the testing area. The average values are reported here and were used for the subsequent tensile property determinations. The film samples with a thickness of $0.75 \pm 0.10 \mathrm{~mm}$ were cut into $25 \times 100 \mathrm{~mm}^{2}$ strips using an extra sharp blade. The samples were then preconditioned in a relative humidity (RH)-controlled chamber $(50 \pm 5 \% \mathrm{RH})$ using a saturated salt solution of magnesium nitrate for $24 \mathrm{~h}$, in accordance with the method of Wongsasulak et al. ${ }^{17}$

Tensile property characterization. The tensile properties of the preconditioned filmstrips were measured using a texture analyzer (TA.XT.Plus, Stable Micro Systems, Surrey, UK) with a 50-kg load cell. The grip surfaces were lined with thin silicone to prevent slippage or breakage of the gripped filmstrips. The initial grip separation was $50 \mathrm{~mm}$, and the crosshead speed was $50 \mathrm{~mm} \mathrm{~min}^{-1}$. Tensile strength, elongation and tensile modulus were defined and calculated as described by Wongsasulak et al. ${ }^{17}$ For each film sample, the tensile property examination was performed on 15 replicates, and the average values are reported. Only the tested samples that ruptured near the mid-specimen length were taken into account for the tensile property calculation.

Fourier-transform infrared spectroscopy and X-ray diffraction. Infrared spectra of the nanofibrous films were recorded using a Fouriertransform infrared spectrometer (Spectrum GX, Perkin-Elmer, Wellesley, MA, USA) operated in a wavelength range of $4000-400 \mathrm{~cm}^{-1}$. Each measurement comprised an average of 16 scans at a resolution of $4 \mathrm{~cm}^{-1}$. For characterizing the crystallinity of the samples, an X-ray diffraction (XRD) pattern for each sample was obtained using a Rigaku MiniFlex (Rigaku, Tokyo, Japan) equipped with a $\mathrm{Cu} \mathrm{K} \alpha$ radiation source. Samples were scanned over the range of $2 \theta=3-70^{\circ}$. 
Differential scanning calorimetry. The phase-transition temperatures of the electrospun films were determined using a differential scanning calorimetry (DSC; DSC $822^{\mathrm{e}}$, Mettler Toledo, Zürich, Switzerland). The measurements were conducted under a nitrogen atmosphere. The samples weighing $3.5 \pm 0.2 \mathrm{mg}$ were hermetically sealed in a DSC pan. An empty pan was used as a reference. The temperature was increased from 25 to $150{ }^{\circ} \mathrm{C}$, from 150 to $25^{\circ} \mathrm{C}$ and from 25 to $200^{\circ} \mathrm{C}$ according to the temperatures of the first heating, subsequent cooling and the second heating, respectively. The scanning rate was $20^{\circ} \mathrm{C} \mathrm{min}-1$. The transition temperature was indicated by the DSC software (STARe Thermal Analysis System, version 6.1, Mettler Toledo). The reported data represent an average of five replicates.

Morphology determination using scanning electron microscopy. The morphologies of the electrospun fibers were investigated using scanning electron microscopy (SEM; JSM-5800, JEOL, USA). The average fiber diameter of each sample was determined by image analysis (Image J, National Institutes of Health (NIH), Bethesda, MD, USA) of 200 fibers. In a typical protocol, the samples were cut into $0.5 \times 0.5 \mathrm{~cm}^{2}$ squares, attached to the sample holder and sputter-coated with gold using coating conditions of $2 \mathrm{kV}$ and $5 \mathrm{~mA}$ for $2 \mathrm{~min}$.

Moisture-adsorption kinetics. An electrospun film sample was cut into $2.5 \times 2.5 \mathrm{~cm}^{2}$ squares. The sample was then dried at $40{ }^{\circ} \mathrm{C}$ for $24 \mathrm{~h}$ in a vacuum oven and subsequently equilibrated in a $\mathrm{RH}$-controlled chamber $(50 \pm 5 \%)$ at $30^{\circ} \mathrm{C}$ for 12 days. The moisture uptake of the samples was periodically measured at $0,12,24,48,72,96,240$ and $288 \mathrm{~h}$ (12 days) using the oven-drying method.

Statistical analysis. Differences among the resulting or tested values were analyzed using one-way analysis of variance. Duncan's multiple range tests at a $95 \%$ significance level $(P<0.05)$ were applied using the statistical software SPSS Inc. (Chicago, IL, USA) (version 15). The data are expressed as the mean \pm s.d.

\section{RESULTS AND DISCUSSION}

This research was conducted to electrospin fibrous films from a CA and PEO blend that contained $\mathrm{ZnO}$ NPs. The effects of PEO and $\mathrm{ZnO}$ NPs on the solution properties, which govern the morphology as well as tensile properties of the electrospun fibrous film, were investigated along with the moisture-adsorption profile of the film samples.

\section{Preliminary study of polymer solution concentrations of CA and PEO}

Han et al. ${ }^{18}$ reported that CA electrospun fibers could be fabricated from a $17 \%(\mathrm{w} / \mathrm{v})$ of CA in $75 \%$ acetic acid, whereas Wongsasulak et al. ${ }^{9}$ reported that the same could be prepared using a solution of $17 \%(\mathrm{w} / \mathrm{v}) \mathrm{CA}$ in $85 \%$ acetic acid. The effects of both solvents as well as that of neat acetic acid (99.99\%) were investigated, as shown in Figures 1a-c. CA in 75\% (Figure 1a) and 85\% (Figure 1b) (v/v) acetic acid solutions resulted in beaded fibers with diameters on the nanometer-length scale. However, the electrospun fibers prepared in 99\% acetic acid showed smooth surfaces (Figure 1c). Although the materials dwelled in ribbon-like structures with a few beads, neat acetic acid was a more suitable solvent for CA than its diluted counterpart. Nevertheless, the presence of beads on the surface and the ribbon structure of the materials led to a hypothesis that the CA concentration was insufficient. The CA concentration was therefore increased to $20 \%(\mathrm{w} / \mathrm{v})$. At this concentration, the beads were no longer obtained (Figure 1d). As a consequence, $20 \%(\mathrm{w} / \mathrm{v})$ of CA in 99.9\% acetic acid was prepared as a stock solution for further experiments.
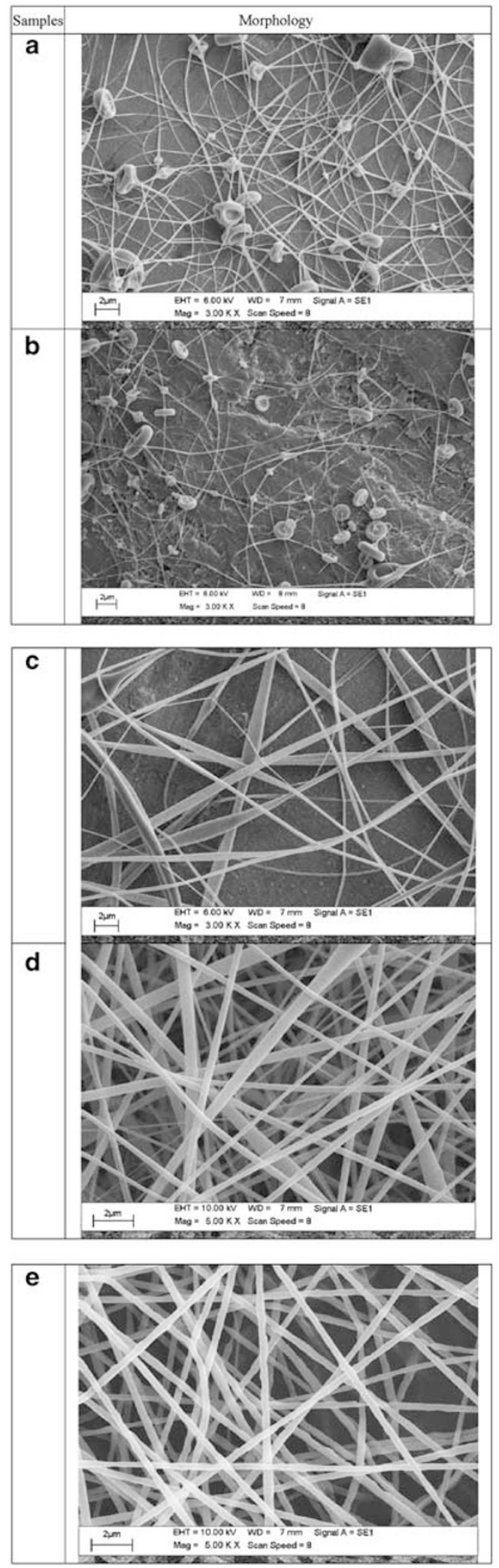

Figure 1 Scanning electron microscopy images of electrospun fibers prepared from $17 \%(\mathrm{w} / \mathrm{v})$ cellulose acetate (CA) in acetic acid (a-c) at acid concentrations of (a) $75 \%$ (b) $85 \%$ (c) $99.9 \%$ (neat conditions) from (d) $20 \%(\mathrm{w} / \mathrm{v}) \mathrm{CA}$ in neat acetic acid and from (e) $3 \%(\mathrm{w} / \mathrm{v})$ poly(ethylene oxide) in $90 \%$ ethanol. EHT, electron high tension; WD, working distance. 

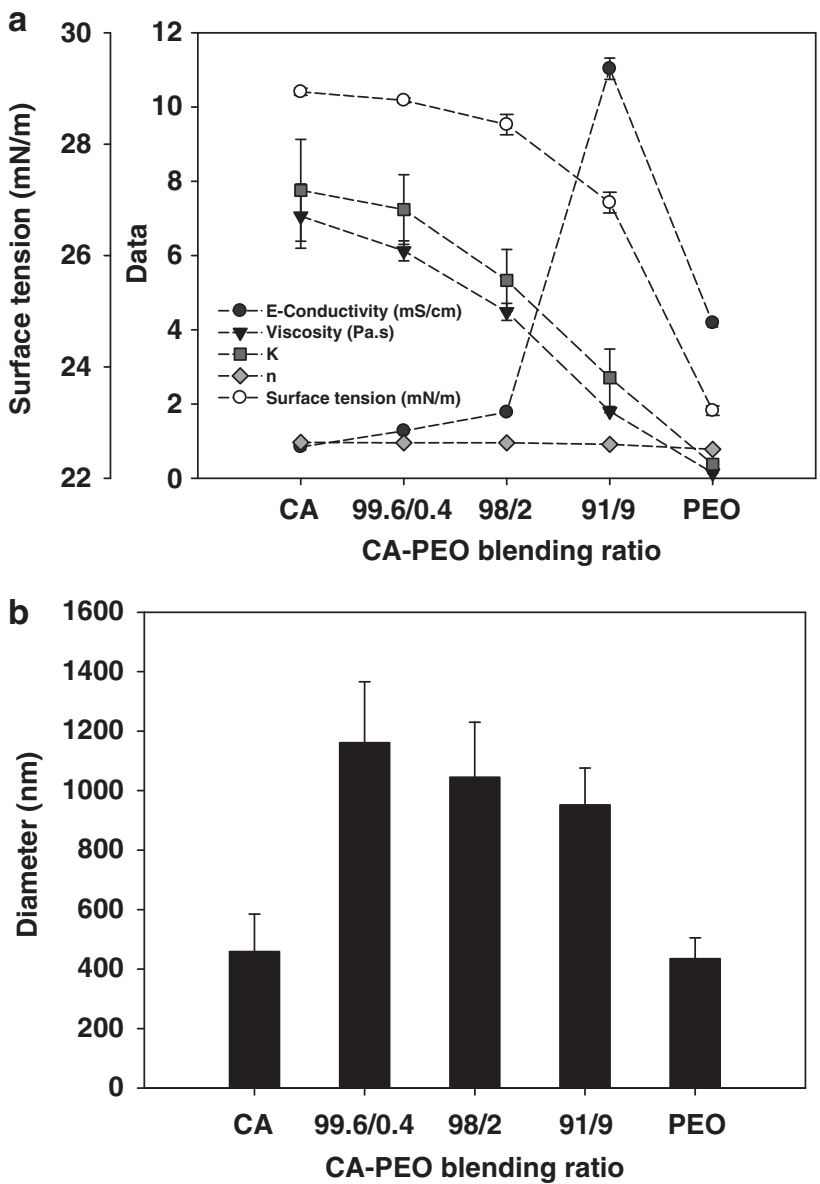

Figure 2 (a) Apparent viscosity at a shear rate of $100 \mathrm{~s}^{-1}$, power law indices; the $K$ and $n$, surface tension; and electrical conductivity of cellulose acetate (CA)-poly(ethylene oxide) (PEO)-blend solutions; and the weight ratio of CA/PEO was 100/0, 99.6/0.4, 98/2, 91/9 or 0/100. The solid content of each solution was fixed at $20 \%(\mathrm{w} / \mathrm{v})$. (b) The average fiber diameter of the electrospun films obtained from each solution sample. A full color version of this figure is available at Polymer Journal online.

The concentration of the PEO primary solution was similarly optimized. The PEO content was varied at 2 and $3 \%(\mathrm{w} / \mathrm{v})$ in ethanol; the concentration of the ethanol was varied at 80,90 or $99.7 \%$. The solution with 3\% (w/v) PEO in $90 \%$ ethanol led to the formation of fine fibers (Figure 1e), but the other combinations did not. The use of absolute ethanol (99.7\%) resulted in an insoluble PEO solution.

Effect of PEO on the solution properties, morphology, and tensile- and moisture-adsorption properties of the CA-PEO-blend electrospun fibrous film

Solution properties. Solution properties, including the viscosity, surface tension and electrical conductivity of CA-PEO-blend solutions prepared from different CA/PEO ratios, that is, 100/0, 99.6/0.4, 98/2, 91/9 and 0/100, were investigated. The results are illustrated in Figure 2a. The surface tension values of the pure CA and PEO solutions were $28.94 \pm 0.06$ and $23.22 \pm 0.09 \mathrm{mN} \mathrm{m}^{-1}$, respectively. The addition of PEO to the CA solution at $0.4,2$ and $9 \mathrm{wt} \%$ resulted in a decrease in the surface tension to $28.79 \pm 0.04,28.35 \pm 0.18$ and $26.95 \pm 0.19 \mathrm{mN} \mathrm{m}^{-1}$, respectively. The apparent viscosity of the pure CA and pure PEO solutions were 6.929 \pm 0.664 and $0.140 \pm 0.009 \mathrm{~Pa}$, respectively. When the percentage of PEO added to the CA solution

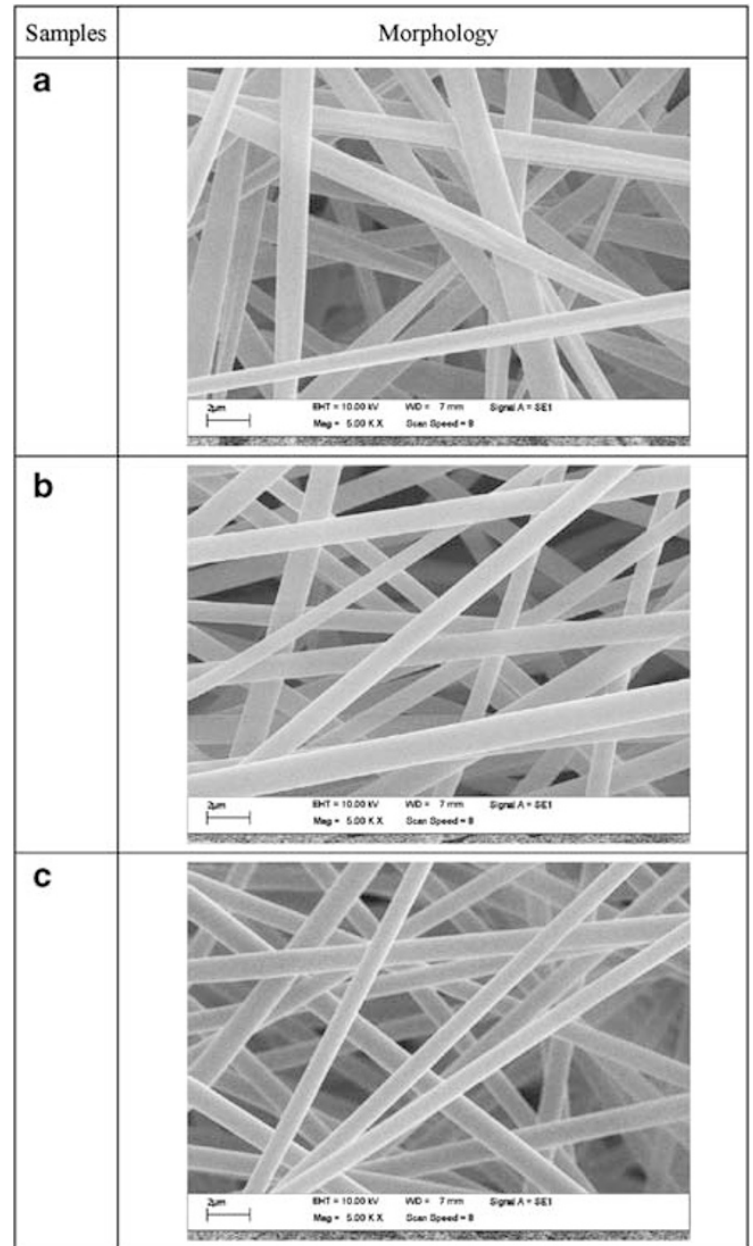

Figure 3 Scanning electron microscopy images of electrospun fibers prepared from cellulose acetate (CA)-poly(ethylene oxide) (PEO)-blend solutions; the CA/PEO ratios were (a) $99.6 / 0.4$, (b) $98 / 2$ and (c) $91 / 9$.

was increased from 0.4 to $9 \mathrm{wt} \%$, the apparent viscosity and flow consistency coefficient $(K)$ of the blend significantly decreased from $6.13 \pm 0.27$ to $1.80 \pm 0.04 \mathrm{Pas}(P<0.05)$ and from $7.24 \pm 0.94$ to $2.71 \pm 0.77 \mathrm{Pas}(P<0.05)$, respectively. However, the flow behavior index $(n)$ of the blends was not affected by the PEO component $(P \geqslant 0.05)$. The electrical conductivity of pure $\mathrm{CA}$ and pure $\mathrm{PEO}$ solutions were $0.844 \pm 0.077$ and $4.187 \pm 0.107 \mu \mathrm{S} \mathrm{cm}^{-1}$, respectively. The blending of CA solution with the PEO solution resulted in an increase in electrical conductivity $(P<0.05)$, especially at the CA/PEO ratio of $91 / 9$, which was likely due to a synergistic effect that led to a substantial electrical conductivity $\left(11.03 \pm 0.29 \mu \mathrm{S} \mathrm{cm}^{-1}\right)$ of the blend. The increase in electrical conductivity could be due to greater extent of acid dissociation in the blend solution, which was attributed to the increase in water content as a result of the increase in the PEO (in 75\% ethanol) blending ratio.

Morphology and component characterization. All the fiber samples, which included pure CA, pure PEO and CA-PEO-blends, were electrospun at an applied voltage of $4-8 \mathrm{kV}$, with a tip-to-target distance of $20 \mathrm{~cm}$ and from a spinneret inner diameter of $\sim 0.69 \mathrm{~mm}$. The flow rate of the sample was set at $10-15 \mu \mathrm{min}^{-1}$. 
The average fiber diameters of all the samples are shown in Figure 2b, and their morphologies are shown in Figure 3. The diameters of the CA and PEO fibers were $459 \pm 126$ and $435 \pm 70 \mathrm{~nm}$, respectively. The standard deviation of the diameters presented in Figure $2 \mathrm{~b}$ indicated that the uniformity of the PEO electrospun fibers was better than that of their CA counterparts. Normally, polymer solutions with a lower flow behavior index $(n)$ impart shear-thinning properties. These distinctive shear-thinning properties, as well as a lower observed surface tension, were believed to be important factors that promoted the diameter uniformity of the PEO fibers. ${ }^{19}$ The addition of PEO significantly increased the diameter of the electrospun CA-PEO-blend fibers $(P<0.05)$ approximately two- to threefold $(\sim 950-1170 \mathrm{~nm})$ and resulted in a smoother fiber surface (Figure 3 ) compared with the pure CA fibers. The addition of small amounts of PEO to the CA resulted in a significant increase in the CA-PEO composite electrospun fiber diameter, as evidenced in Figure $2 \mathrm{~b}$. This phenomenon can be explained by first considering only pure PEO, which possesses a relatively low viscosity of $0.14 \mathrm{~Pa}$ s. After CA, which exhibits a much higher viscosity of 6.93 Pa s, was blended into the PEO either at 91, 98 or $99.6 \mathrm{wt} \%$, however, the higher viscosity of CA led to an increase in the viscosity of the mixture solution. This increase in viscosity resulted in a CA-PEO composite fiber with a larger diameter. In fact, such a high viscosity of CA should have led to the production of even thicker fibers. Nevertheless, because of the nature of CA (low entanglement) and the high surface tension of CA in acetic acid, the polymer chain could not be stretched into large fibers, which eventually resulted in only short and very fragile CA fibers. This phenomenon was also observed during our previous study. ${ }^{9}$ However, the range of PEO blending ratios used in this study did not yield differences in the blend's fiber diameters $(P \geqslant 0.05)$. Even though the viscosity of these blends was significantly reduced, the diameters of the resulting fibers were not affected because the lower viscosity influence was balanced by the lower surface tension and higher electrical conductivity of the blend solution. In general, these two effects yield larger electrospun fibers. These results suggested that the fine morphology of the electrospun fibers can be successfully created by the proper modulation of the solution properties; similar results have also been reported by other researchers. ${ }^{9,17,19-25}$

The Fourier-transform infrared spectra of the electrospun CA fibers showed a strong ester carbonyl stretching vibration at $1750 \mathrm{~cm}^{-1}, 26$ whereas those of PEO fibers exhibited strong peaks at $2900 \mathrm{~cm}^{-1}$ that were attributed to the molecular stretching of methylene groups $\left(\mathrm{CH}_{2}\right){ }^{9}$ The Fourier-transform infrared spectra of the CA-PEO fibers exhibited both of these characteristic peaks, as shown in Figure 4. The spectra also showed that two original characteristic peaks (at 1630 and $900 \mathrm{~cm}^{-1}$ ) of CA slightly shifted to lower wave numbers when PEO was added. The signal strength also decreased as the PEO ratio was increased. Because the PEO molecules $(300 \mathrm{kDa})$ are larger than those of CA $(30 \mathrm{kDa})$, the average molecular weight of the blend polymers became larger, as indicated by the lower wave numbers and decreasing signal strength of the blend molecules compared with those of CA. In addition, the circled peak in the figure shows that the original characteristic CA peaks at 1150 and $1125 \mathrm{~cm}^{-1}$ changed more significantly as the PEO blending ratio was increased from 0.4 to $9 \mathrm{wt} \%$. The blends exhibited characteristic peaks between those of CA $\left(1150\right.$ and $\left.1125 \mathrm{~cm}^{-1}\right)$ and PEO $\left(890 \mathrm{~cm}^{-1}\right)$, which might be due to entanglement between the $\mathrm{CA}$ and $\mathrm{PEO}$ polymer chains.

Tensile properties. The effects of the PEO content of the CA-PEOblend electrospun fibers on the tensile properties are reported in

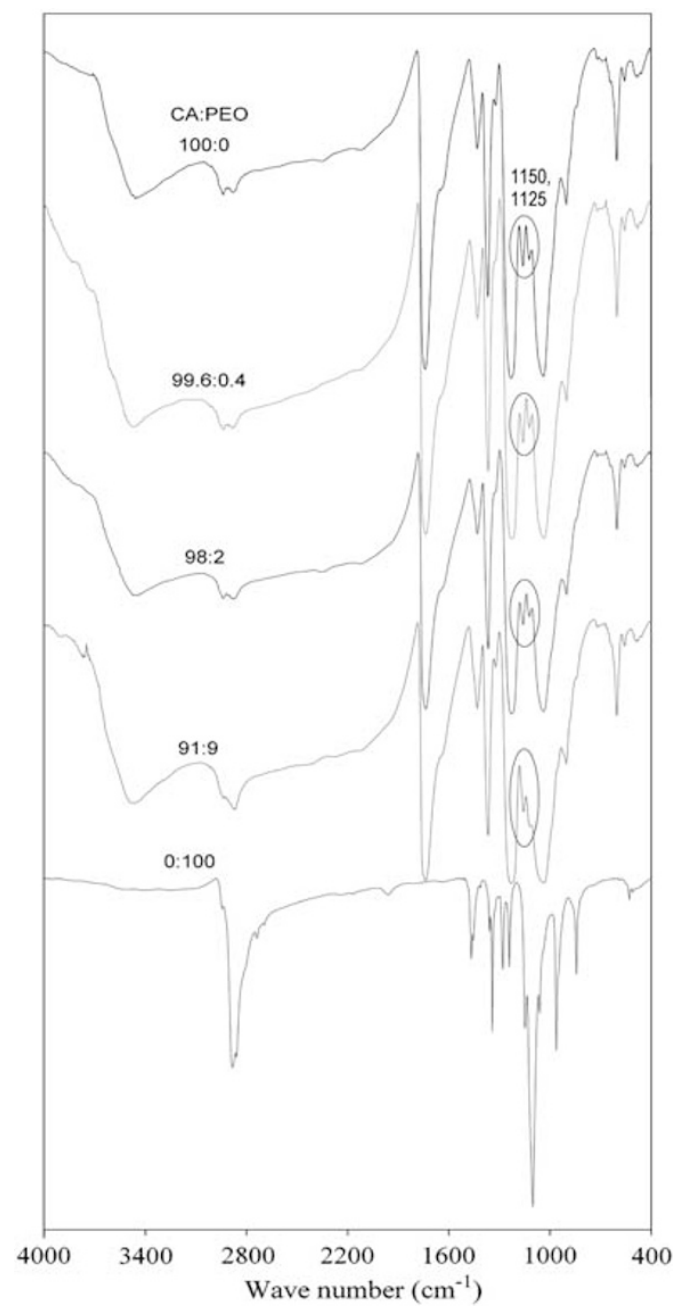

Figure 4 Fourier-transform infrared spectra acquired over a wave number range of $4000-400 \mathrm{~cm}^{-1}$ of electrospun fibers fabricated from cellulose acetate (CA)/poly(ethylene oxide) (PEO)-blend ratios (from top to bottom) of 100/0 (pure CA), 99.6/0.4, 98/2, 91/9 and 0/100 (pure PEO). A full color version of this figure is available at Polymer Journal online.

Table 1. The tensile strength, elongation and elastic modulus at break of the CA fibrous films were $0.448 \pm 0.062 \mathrm{MPa}, 10.59 \pm 1.66 \%$ and $0.043 \pm 0.005 \mathrm{MPa}$, respectively, and for the PEO electrospun films they were $4.162 \pm 0.381 \mathrm{MPa}, 27.05 \pm 2.23 \%$ and $0.154 \pm 0.014 \mathrm{MPa}$, respectively. The inclusion of PEO in the CA electrospun fibers resulted in higher tensile strength, elongation and elastic modulus at break of the blend's fibrous films. The improved tensile properties of the CA-PEOblends could be due to the crystalline structure of the PEO molecules. ${ }^{27}$ In general, when crystalline polymers are stretched, the polymer chains become oriented in the direction of the stress. As such, the phenomenon called 'necking' is then observed, ${ }^{27}$ which leads to higher tensile properties of the polymer. Because the CA-PEO fibrous film prepared at a CA/PEO ratio of 91/9 exhibited the highest tensile performance, this blending ratio was chosen for the preparation of CA-PEO electrospun films containing $\mathrm{ZnO}$ NPs in the subsequent study.

Moisture-adsorption kinetics. Moisture adsorption has a significant role in food packaging. This phenomenon, together with other physical properties of films, offers varying degrees of preservation for the contained products. The moisture adsorption of CA-PEO 
Table 1 Tensile properties of fibrous thin films electrospun from (A) the blend polymer of CA and PEO without ZnO NPs and (B) the CA-PEOblend (91/9) with ZnO NPs

\begin{tabular}{|c|c|c|c|c|}
\hline \multirow[b]{2}{*}{ Test } & \multirow[b]{2}{*}{ Blending ratio } & \multicolumn{3}{|c|}{ Tensile properties } \\
\hline & & Tensile strength ( $\mathrm{MPa}$ ) & Elongation at break (\%) & Elastic modulus ( $\mathrm{MPa} / \%$ ) \\
\hline & (CA/PEO) & & & \\
\hline \multirow[t]{6}{*}{ A } & $100 / 0$ & $0.448 \pm 0.062^{a}$ & $10.586 \pm 1.661^{a}$ & $0.043 \pm 0.005^{a}$ \\
\hline & $99.6 / 0.4$ & $0.819 \pm 0.099^{b}$ & $11.555 \pm 1.057^{a}$ & $0.072 \pm 0.012^{b}$ \\
\hline & $98 / 2$ & $1.928 \pm 0.233^{c}$ & $13.789 \pm 0.611^{b}$ & $0.140 \pm 0.019^{c}$ \\
\hline & $91 / 9$ & $2.446 \pm 0.274^{d}$ & $16.286 \pm 1.520^{c}$ & $0.152 \pm 0.024^{c}$ \\
\hline & $0 / 100$ & $4.162 \pm 0.381^{e}$ & $27.048 \pm 2.227^{d}$ & $0.154 \pm 0.014^{c}$ \\
\hline & With ZnO NP (wt\% of & & & \\
\hline \multirow[t]{4}{*}{ B } & 0 & $2.446 \pm 0.274^{a}$ & $16.286 \pm 1.520^{\mathrm{a}}$ & $0.152 \pm 0.024^{a}$ \\
\hline & 2 & $2.641 \pm 0.195^{a}$ & $17.071 \pm 0.774^{a, b}$ & $0.155 \pm 0.012^{\mathrm{a}}$ \\
\hline & 10 & $3.323 \pm 0.557^{b}$ & $17.733 \pm 0.799^{b}$ & $0.189 \pm 0.038^{b}$ \\
\hline & 20 & $3.607 \pm 0.488^{b}$ & $18.185 \pm 0.584^{b}$ & $0.199 \pm 0.029^{b}$ \\
\hline
\end{tabular}

Abbreviations: CA, cellulose acetate; NP, nanoparticle; PEO, poly(ethylene oxide); ZnO, zinc oxide.

The different letters $(a-e)$ in the same column of each test indicate the significant differences $(P<0.05)$ of the values.

The reported values are presented in terms of mean \pm s.d., which were obtained from 10 replication determinations.

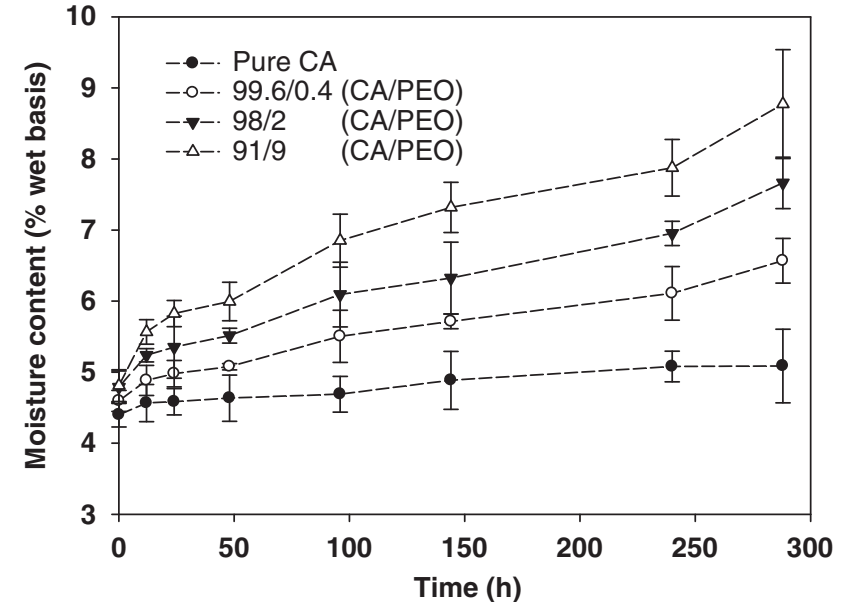

Figure 5 The moisture-adsorption profiles of electrospun films with cellulose acetate (CA)/poly(ethylene oxide) (PEO) blend ratios of 100/0 (pure CA), 99.6/0.4, 98/2, 91/9 and 0/100 (pure PEO); the film samples were equilibrated in a RH-controlled chamber at $50 \pm 5 \% \mathrm{RH}$ at $25 \pm 1{ }^{\circ} \mathrm{C}$.

nanofibrous films was studied in a controlled chamber with a $\mathrm{RH}$ of $50 \pm 5 \%$ at $25 \pm 1{ }^{\circ} \mathrm{C}$ for 12 days. The moisture content of each sample was determined periodically. As shown in Figure 5, the moisture adsorption increased linearly as a function of time in the case of CA fibrous films. However, a deviation from linearity was observed in the case of the CA-PEO-blend fibrous films. From the figure, the average initial moisture content of the fibrous films was $\sim 4.65 \%(P \geqslant 0.05)$. After the film samples were aged in the RH-controlled chamber $(50 \pm 5 \% \mathrm{RH})$ at $28 \pm 1{ }^{\circ} \mathrm{C}$ for 12 days, the moisture contents of the films increased to $5.09 \pm 0.52,6.57 \pm 0.31,7.66 \pm 0.36$ and $8.77 \pm 0.77 \%$ for the CA film and the $99.6 / 0.4$, 98/2 and 91/9 CAPEO-blend fibrous films, respectively.

Effect of ZnO NPs on the morphology, thermal and tensile properties of the CA-PEO-blend electrospun fibrous film Morphology. The morphologies of the electrospun CA-PEO-blend fibers containing $\mathrm{ZnO} \mathrm{NP}$ composite electrospun fibers were exam-

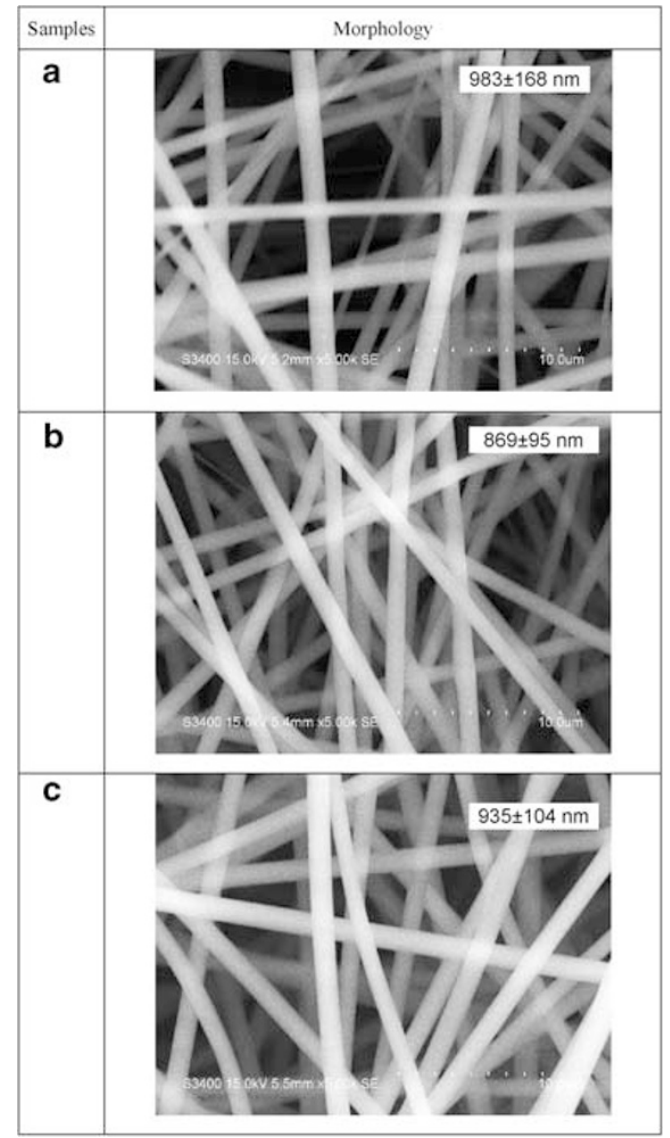

Figure 6 Scanning electron microscopy images of electrospun cellulose acetate-poly(ethylene oxide) (PEO)-blend fibers (91/9) containing zinc oxide nanoparticles at concentrations of (a) 2 (b) 10 and (c) 20 wt $\%$ of PEO. 


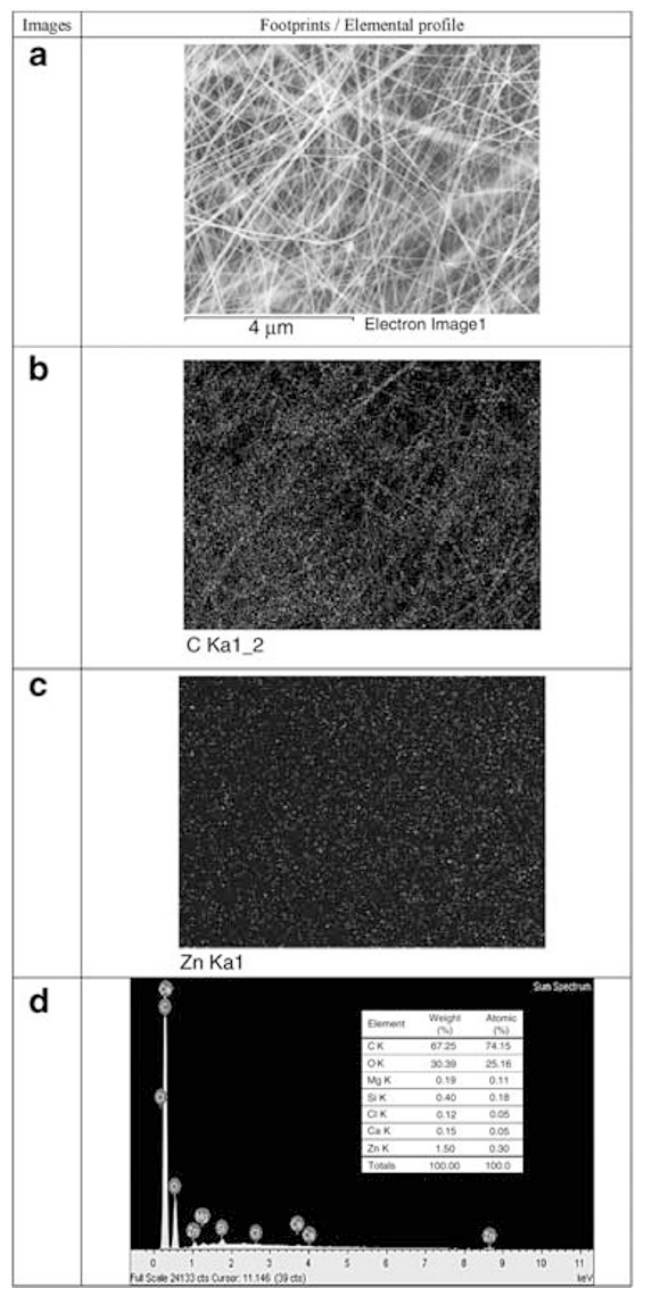

Figure 7 (a) Backscattered electron image of the electrospun cellulose acetate-poly(ethylene oxide)-zinc oxide nanoparticle composite fibers. (b) Elemental distribution maps of carbon in the nanocomposite fibers. (c) Elemental distribution maps of $\mathrm{Zn}$ in the nanocomposite fibers. (d) An energy-dispersive spectrometer profile of elements in the nanocomposite fibers. A full color version of this figure is available at Polymer Journal online. ined using SEM; the results are shown in Figure 6. All fiber samples showed smooth surfaces with homogenous rod-like structures. The diameters of the composite fibers with $\mathrm{ZnO} \mathrm{NP}$ ratios of 2, 10 and $20 \mathrm{wt} \%$ were $983 \pm 168,869 \pm 95$ and $935 \pm 104 \mathrm{~nm}$, respectively. However, the presence of ZnO NPs was not observed in the SEM micrographs. Therefore, the energy-dispersive spectrometer (EDS) mode was used to detect the footprints of $\mathrm{ZnO}$ within the nanocomposite fibers. The EDS maps (Figures $7 \mathrm{a}-\mathrm{c}$ ) show the localization of carbon (C; Figure 7b) and zinc ( $\mathrm{Zn}$ ) elements (Figure 7c) on the films. The reliability of the EDS-SEM results was supported by EDS element profiles, as shown in Figure $7 \mathrm{~d}$. The results indicated that the $\mathrm{ZnO}$ NPs were co-electrospun and well dispersed in the CA-PEO fiber matrix. The good dispersion of $\mathrm{ZnO}$ NPs within the fiber matrix was due to the rapid-solidification phenomenon of the electrospinning flying jet before it reached the grounded collector plate. Electrospinning, hence, offers an effective method for the formation of nanocomposite nanofibers.

Thermal properties of the $\mathrm{CA}-\mathrm{PEO}-\mathrm{ZnO}$ nanocomposite fibrous films. The thermal properties of the CA-PEO-ZnO nanocomposite fibrous films were characterized using DSC. The thermograms of the samples are not shown, but the obtained results are summarized in Table 2. PEO exhibited only one transition temperature, at $\sim 67^{\circ} \mathrm{C}$, whereas CA showed two transition peaks, at approximately 87 and $226^{\circ} \mathrm{C}$. For the CA-PEO-ZnO nanocomposite fibrous films, two transition peak regions were observed $\left(\sim 78-88\right.$ and $\left.\sim 224-226^{\circ} \mathrm{C}\right)$. The occurrence of these peaks suggested the presence of both CA and PEO. As the concentration of $\mathrm{ZnO}$ NPs in the fibrous films was increased from 2 to $20 \%$, the first transition temperature increased from 78 to $88^{\circ} \mathrm{C}$. The inclusion of $\mathrm{ZnO}$ NPs resulted in a change in only the first transition temperature without affecting the second one, which indicated that the ZnO NPs are mainly incorporated into the PEO molecules. The change in the phase-transition temperature can be explained by $\mathrm{ZnO}$ NPs interacting with the crystalline structure of the PEO molecules, thereby restricting the mobility of the PEO molecular chains. The effect of ZnO NPs in improving crystallinity of PEO in the tri-composite structure was confirmed by two-dimensional XRD spectra, as shown in Figure 8. The results indicate that $\mathrm{ZnO}$ NPs enhanced the crystalline structure of PEO in the composite fibers. The $2 \theta$ diffraction peaks of PEO at 14 and $16^{\circ}$ (noted by the

Table 2 Phase transition temperatures of fibrous films electrospun from (A) the CA-PEO-blend without ZnO and (B) the CA-PEO (91/9) with $\mathrm{ZnO}$

\begin{tabular}{|c|c|c|c|c|c|c|c|c|c|}
\hline \multirow[b]{2}{*}{ Test } & \multirow[b]{2}{*}{ Samples } & \multicolumn{3}{|c|}{ First transition } & \multirow[b]{2}{*}{ Energy $\left(\mathrm{Jg}^{-1}\right)$} & \multicolumn{3}{|c|}{ Second transition } & \multirow[b]{2}{*}{ Energy $\left(\mathrm{Jg}^{-1}\right)$} \\
\hline & & Onset & Peak & End set & & Onset & Peak & End set & \\
\hline & CA/PEO & & & & & & & & \\
\hline \multirow[t]{6}{*}{ A } & Pure CA & $55.1 \pm 1.2$ & $87.4 \pm 1.5$ & $115.7 \pm 2.2$ & 96.17 & $216.2 \pm 1.0$ & $225.8 \pm 1.2$ & $231.2 \pm 1.0$ & 7.88 \\
\hline & $99.6 / 0.4$ & $54.9 \pm 1.4$ & $85.1 \pm 1.7$ & $68.2 \pm 2.0$ & 68.2 & $216.8 \pm 1.1$ & $224.5 \pm 1.1$ & $230.1 \pm 1.5$ & 7.03 \\
\hline & $98 / 2$ & $58.6 \pm 1.5$ & $95.8 \pm 1.8$ & $124.3 \pm 1.7$ & 83.89 & $216.1 \pm 0.9$ & $224.4 \pm 1.0$ & $229.9 \pm 1.2$ & 6.58 \\
\hline & $91 / 9$ & $56.9 \pm 1.1$ & $91.2 \pm 1.5$ & $119.3 \pm 2.1$ & 66.08 & $215.9 \pm 1.0$ & $225.9 \pm 0.8$ & $231.3 \pm 1.3$ & 7.00 \\
\hline & Pure PEO & $60.7 \pm 1.2$ & $66.6 \pm 1.0$ & $72.1 \pm 1.2$ & 146.02 & - & - & - & - \\
\hline & \multicolumn{9}{|c|}{ CA-PEO-ZnO composite (wt\% of ZnO NP) } \\
\hline \multirow[t]{3}{*}{ B } & 2 & $51.4 \pm 0.9$ & $78.0 \pm 0.8$ & $102.2 \pm 1.1$ & 47.05 & $218.2 \pm 1.7$ & $226.5 \pm 1.4$ & $233.3 \pm 1.8$ & 7.13 \\
\hline & 10 & $50.9 \pm 1.0$ & $82.7 \pm 0.8$ & $108.7 \pm 0.9$ & 44.46 & $216.4 \pm 1.2$ & $224.4 \pm 1.2$ & $230.3 \pm 1.7$ & 2.84 \\
\hline & 20 & $55.4 \pm 0.8$ & $87.5 \pm 0.7$ & $115.8 \pm 0.9$ & 48.13 & $218.7 \pm 1.4$ & $224.1 \pm 1.5$ & $230.7 \pm 1.4$ & 2.66 \\
\hline
\end{tabular}

Abbreviations: CA, cellulose acetate; NP, nanoparticle; PEO, poly(ethylene oxide); ZnO, zinc oxide.

The ratio of ZnO NPs is stated as the ZnO NP wt\% ratio of PEO.

The reported values are presented in terms of mean \pm s.d., which were obtained from five-replication determinations. 


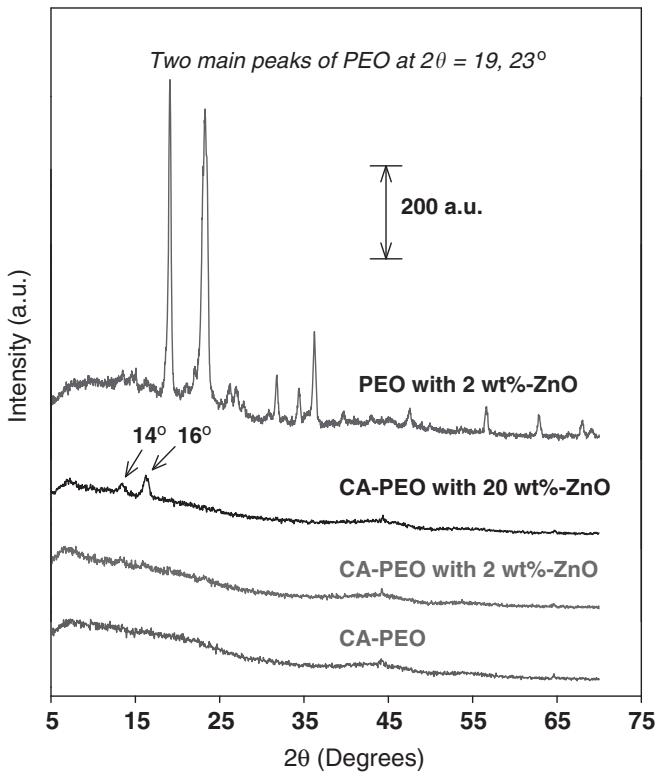

Figure 8 Two-dimensional X-ray diffraction (XRD) patterns of nanocomposite electrospun samples; from bottom to top are the XRD spectra of the cellulose acetate (CA)-poly(ethylene oxide) (PEO) composite fibers, CA-PEO with zinc oxide nanoparticles (ZnO NPs; 2 and $20 \mathrm{wt} \%$ of PEO) nanocomposite fibers and $\mathrm{PEO}$ with $2 \mathrm{wt} \% \mathrm{ZnO}$ nanocomposite fibers. A full color version of this figure is available at Polymer Journal online.

pointed arrows in the figure) were not detected in the CA-PEO composite. However, these peaks were detected after the $\mathrm{ZnO}$ NPs were included. The characteristic peaks were more noticeable as the content of the $\mathrm{ZnO}$ NPs was increased to $20 \mathrm{wt} \%$. A similar result has been reported by Li et al. ${ }^{28}$

Tensile properties. The electrospun fibrous films of CA-PEO-blends containing $\mathrm{ZnO}$ NPs at 2, 10 and $20 \mathrm{wt} \%$ were aged in a controlled $\mathrm{RH}$ chamber $(50 \pm 5 \%)$ at $25 \pm 1{ }^{\circ} \mathrm{C}$ for $24 \mathrm{~h}$ before the tensile property testing. As summarized in Table 1, the addition of $\mathrm{ZnO}$ NPs to the CA-PEO electrospun nanofibrous films at $1.8 \mathrm{wt} \%$ increased the tensile strength, elongation at break and elastic modulus of the blend fibrous films by $47 \%, 12 \%$ and $31 \%$, respectively. With respect to the DSC results, the ZnO NPs may have facilitated the orientation of the PEO polymer chains. The role of NPs in improving the mechanical properties of fibers, which was attributed to polymer chain orientation, have similarly been discussed by Lepot et al., ${ }^{6}$ Lee et al. ${ }^{29}$ and Xia et al. ${ }^{30}$

\section{CONCLUSION}

This study focused on the use of PEO and $\mathrm{ZnO}$ NPs as functional additives for improving the tensile properties of CA fibrous films as food-packaging materials. The tri-component fibrous films were fabricated by the electrospinning technique, which yielded continuously long, smooth, ultrafine fibers with approximate diameters of $800-900 \mathrm{~nm}$. The addition of $9 \mathrm{wt} \%$ PEO improved the tensile strength, elongation and elastic modulus at break of the original CA electrospun film by $446 \%, 54 \%$ and $253 \%$, respectively. The addition of $20 \mathrm{wt} \% \mathrm{ZnO} \mathrm{NP}$ into the CA-PEO-blend electrospun films improved the tensile strength, elongation and elasticity of the nanofibrous films by $47 \%, 12 \%$ and $31 \%$, respectively. As suggested by the DSC and XRD results, the tensile properties of the CA-PEO electro- spun films that contained $\mathrm{ZnO}$ NPs were improved through the incorporation of $\mathrm{ZnO}$ NPs into the PEO matrix. Although $\mathrm{ZnO}$ NPs have been noted for their potential antibacterial properties, the risk associated with the use of such nanoparticles is still unclear. Because the CA-PEO-ZnO nanocomposite fibrous films are expected to be applied in food packaging, the nanoparticle exposure risks must be evaluated. An investigation of these risks is currently being performed in our laboratory.

\section{CONFLICT OF INTEREST}

The authors declare no conflict of interest.

\section{ACKNOWLEDGEMENTS}

This research project was financially supported by the National Research University Project of Thailand's Office of the Higher Education Commission for financial support through King Mongkut's University of Technology Thonburi.

1 Sorrentino, A., Gorrasi, G. \& Vittoria, V. Potential perspectives of bio-nanocomposites for food packaging applications. Trend Food Sci. Technol. 18, 84-95 (2007).

2 Liu, Y., He, L., Mustapha, A., Li, H., Hu, Z. Q. \& Lin, M. Antibacterial activities of zinc oxide nanoparticles against Escherichia coli 0157:H7. J. Appl. Microbiol. 107, 1193-1201 (2009).

3 Li, X. H., Xing, Y. G., Li, W. L., Jiang, Y. H. \& Ding, Y. L. Antibacterial and physical properties of poly(vinyl chloride)-based film coated with $\mathrm{ZnO}$ nanoparticles. Food Sci. Technol. Int. 16, 225-232 (2010).

4 Chaurasia, V., Chand, N. \& Bajpai, S. K. Water sorption properties and antimicrobial action of zinc oxide nanoparticles-loaded cellulose acetate films. J. Macromol. Sci. A 47, 309-317 (2010).

5 Jin, T. \& Gurtler, J. B. Inactivation of Salmonella in liquid egg albumen by antimicrobial bottle coatings infused with allyl isothiocyanate, nisin and zinc oxide nanoparticles. J. Appl. Microbiol. 110, 704-712 (2011).

6 Lepot, N., Van Bael, M. K., Van Den Rul, H., D'Haen, J., Peeters, R., Franco, D. \& Mullens, J. Influence of incorporation of $\mathrm{ZnO}$ nanoparticles and biaxial orientation on mechanical and oxygen barrier properties of polypropylene films for food packaging applications. J. Appl. Polym. Sci. 120, 1616-1623 (2011).

7 Emamifar, A., Kadivar, M., Shahedi, M. \& Soleimanian-Zad, S. Effect of nanocomposite packaging containing $\mathrm{Ag}$ and $\mathrm{ZnO}$ on inactivation of Lactobacillus plantarum in orange juice. Food Control 22, 408-413 (2011)

8 Gemili, S., Yemenicioğlu, A. \& Altinkaya, S. A. Development of cellulose acetate based antimicrobial food packaging materials for controlled release of lysozyme. J. Food Eng. 90, 453-462 (2009).

9 Wongsasulak, S., Patapeejumruswong, M., Weiss, J., Supaphol, P. \& Yoovidhya, T. Electrospinning of food-grade nanofibers from cellulose acetate and egg albumen blends. J. Food Eng. 98, 370-376 (2010).

10 Abou-Zeid, N. Y., Waly, A. I., Kandile, N. G., Rushdy, A. A., El-Sheikh, M. A. \& Ibrahim, H. M. Preparation, characterization and antibacterial properties of cyanoethylchitosan/ cellulose acetate polymer blended films. Carbohydr. Polym. 84, 223-230 (2011).

11 John, A., Ko, H. U., Kim, D. G. \& Kim, J. Preparation of cellulose-ZnO hybrid films by a wet chemical method and their characterization. Cellulose 18, 675-680 (2011).

12 Wang, D. \& Sun, G. Novel polymer blends from polyester and bio-based cellulose ester. J. Appl. Polym. Sci. 119, 2302-2309 (2011).

13 Yousefi, H., Faezipour, M., Nishino, T., Shakeri, A. \& Ebrahimi, G. All-cellulose composite and nanocomposite made from partially dissolved micro- and nanofibers of canola straw. Polym. J. 43, 559-564 (2011).

14 Kelner, A. \& Schacht, E. H. Tailor-made polymers for local drug delivery: release of macromolecular model drugs from biodegradable hydrogels based on poly(ethylene oxide). J. Control Release 101, 13-20 (2005).

15 Zhao, H. \& Li, R. K. Y. A study on the photo-degradation of zinc oxide ( $\mathrm{ZnO}$ ) filled polypropylene nanocomposites. Polymer 47, 3207-3217 (2006).

16 Huang, Z. M., Zhang, Y.- Z., Kotaki, M. \& Ramakrishna, S. A review on polymer nanofibers by electrospinning and their applications in nanocomposites. Comp. Sci. Technol. 63, 2223-2253 (2003).

17 Wongsasulak, S., Tongsin, P., Intasanta, N. \& Yoovidhya, T. Effect of glycerol on solution properties governing morphology, glass transition temperature, and tensile properties of electrospun zein film. J. Appl. Polym. Sci. 118, 910-919 (2010).

18 Han, S. O., Youk, J. H., Min, K. D., Kang, Y. O. \& Park, W. H. Electrospinning of cellulose acetate nanofibers using a mixed solvent of acetic acid/water: effects of solvent composition on the fiber diameter. Mater. Lett. 62, 759-762 (2008).

19 Wongsasulak, S., Kit, K. M., McClements, D. J., Yoovidhya, T. \& Weiss, J. The effect of solution properties on the morphology of ultrafine electrospun egg albumen-PEO composite fibers. Polymer 48, 448-457 (2007).

20 Fukushima, S., Karube, Y. \& Kawakami, H. Preparation of ultrafine iniform polyimide nanofibers. Polym. J. 42, 514-518 (2010). 
21 You, Y., Lee, S. J., Min, B. M. \& Park, H. Effect of solution properties on nanofibrous structure of electrospun poly(lactic-co-glycolic acid). J. Appl. Polym. Sci. 99, 1214-1221 (2006).

22 Desai, K. \& Kit, K. Effect of spinning temperature and blend ratios on electrospun chitosan/poly(acrylamide) blends fibers. Polymer 49, 4046-4050 (2008).

23 Homayoni, H., Ravandi, S. A. H. \& Valizadeh, M. Electrospinning of chitosan nanofibers: processing optimization. Carbohydr. Polym. 77, 656-661 (2009).

24 Kriegel, C., Kit, K. M., McClements, D. J. \& Weiss, J. Nanofibers as carrier systems for antimicrobial microemulsions. Part I: Fabrication and characterization. Langmuir 25, 1154-1161 (2009)

25 Wang, Y., Qiao, W., Wang, B., Zhang, Y., Shao, P. \& Yin, T. Electrospun composite nanofibers containing nanoparticles for programmable release of dual drugs. Polym. J. 43, 478-483 (2011).
26 Zhang, L. \& Hsieh, Y. L. Ultra-fine cellulose acetate/poly(ethylene oxide) bicomponent fibers. Carbohydr. Polym. 71, 196-207 (2008).

27 Ramakrishna, S., Fujihara, K., Teo, W. E., Lim, T. C. \& Ma, Z. Electrospinning Process: An Introduction to Electrospinning and Nanofibers 90-101 (World Scientific Publishing, Singapore, 2005).

$28 \mathrm{Li}$, P., Song, G., Yin, L., Wang, L. \& Ma, G. New toughened polypropylene/ organophilic montmorillonite nanocomposites. J. Appl. Polym. Sci. 108, 2116 2121 (2008).

29 Lee, S. Multifunctionality of layered fabric systems based on electrospun polyurethane/zinc oxide nanocomposite fibers. J. Appl. Polym. Sci. 114, 3652-3658 (2008).

30 Xia, Y., Gao, G. \& Li, Y. Preparation and properties of nanometer titanium dioxide/silk fibroin blend membrane. J. Biomed. Mater. Res. B. 90, 653-658 (2009). 